\title{
Mathematical Description Design Process of Plastic Details
}

\author{
Prof. Karimov J.A., Prof.Habibov I.A., Ass.Prof. Malikov R.Kh. \\ Azerbaijan State oil and Industry University
}

It is known that the strength and precision factors are the most important indicators of the quality for plastic parts. At the same time, the precision depends on the magnitude of shrinkage strain. Therefore, it is possible to establish a direct analytical relationship between quality, strength and shrinkage strain factors, which is a function of the difference between the thermal stresses and other physical process. Currently, the difference in thermal stresses (residual stress) is not controlled due to the lack of reliable methods to determine and control their magnitude and direction. However, the magnitude of the volumetric or linear strain of finished products can be controlled by manipulating other quality factors.Determination of the link between volumetric strain and strength is possible by controlling the cooling process of the polymer components under normal operating conditions. Then it's possible to analytically find the change in volumetric strain of the parts and the change in the difference of thermal stresses during cooling. Thus, the volumetric strain is a linear thermal shrinkage, i.e. the change of dimension and geometric shapes in all three directions ( $x, y, z)$ and is controlled by the quality criterion.On the other hand, the cooling process of plastic parts due to their low thermal conductivity is characterized by the cooling gradient of cross section. This leads to the formation of thermo-elastic stresses. The greater the temperature difference between the center and the surface layers, the more stress should be expected. For each infinitesimal layer the difference in the free thermal and total shrinkage rate will be compensated by a different strain.At first, the cooling rate of the outer layers despite the poor thermal conductivity greater than the internal. Further cooling results in a state where the cooling rate of the inner regions is greater than that of the outer. As a result, of this more intensive volume reduction begins in parts of the inner layers. The outer layers prevent this kind of decrease. The resistance of some layers of plastic parts to the shrinkage than that of the others causes thermal stresses, which at high temperatures can cause destruction of the components, if the value of any stress exceeds the tensile strength of the material.After cooling tangential compressive stresses are fixed in the outer layers of plastics and in the internal - tensile. Residual stresses are the greater, the greater the temperature difference over the cross section, the higher the rate of cooling and the lower part of the stresses succeed to relax, the greater are be residual stresses. Therefore, more detailed look shall be given to the distribution patterns of the thermal stresses drop for cylindrical plastic parts when they are cooled (fig.1).

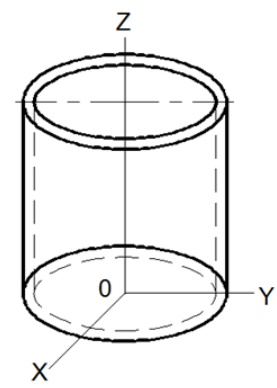

a)

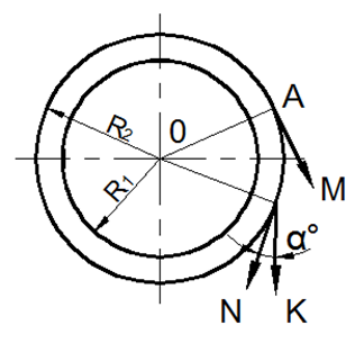

b)

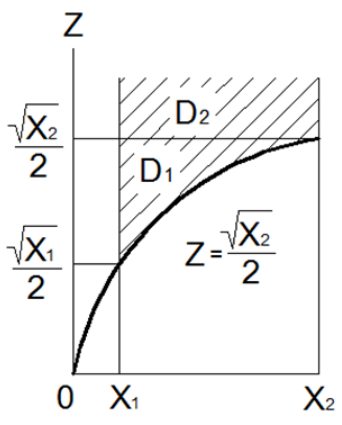

c)

Fiq.1

Assume that uniformly cooled cylinder axis coincides with the axis $o z$. Then, the temperature drop in spite of a poor thermal conductivity $\Delta T$ of isotropic cylindrical body depends on $r, z$, and $t$ and will be determined by the heat conduction equation in cylindrical coordinates.

$\frac{\partial \Delta T}{\partial t}=a\left(\frac{1}{2} \frac{\partial \Delta T}{\partial r}+\frac{\partial^{2} \Delta T}{d r^{2}}+\frac{\partial^{2} \Delta T}{d z^{2}}\right)=a \Delta T(1)$

with the initial conditions

$\Delta T(r, z, 0)=T(r, z, 0)-T_{0}=T_{H}-T_{0}=\Delta T_{H}(2)$

with the boundary conditions 


$$
\left\{\begin{array}{l}
\frac{\partial \Delta T\left(R_{1}, z, t\right)}{\partial r}-\frac{\alpha_{1}}{\lambda} \Delta T\left(R_{1}, z, t\right)=0 \\
\frac{\partial \Delta T\left(R_{2}, z, t\right)}{\partial r}+\frac{\alpha_{2}}{\lambda} \Delta T\left(R_{2}, z, t\right)=0 \\
\frac{\partial \Delta T(z, 0, t)}{\partial z}=0 \\
\frac{\partial \Delta T(r, h, t)}{\partial z}+\frac{\alpha}{\lambda} \Delta T(r, h, t)=0
\end{array}\right.
$$

$a$ - temperature conductivity of material;

$z$-height of cylinder;

$$
\Delta T \text {-Laplace Operator; }
$$

$t$-time;

$R_{1}, R_{2}$-radius of the inner and the outer surface of the hollow cylinder;

$\alpha_{1}, \alpha_{2}, \alpha_{3}$ - the heat exchange coefficient between the cooled body and the environment in the internal part and in the outer surface of the cylinder and in the ends respectively;

$\lambda$ - coefficient of thermal conductivity;

$T(r, z, t)$ - variable temperature.

$T_{0^{-}}$ambient temperature

$$
\Delta T(r, z, t)=T(r, z, t)-T_{0}
$$

According to Duhamel hypothesis, if the inertial effects aren't taken into consideration, then distribution of the thermal stresses is quasi-static. In this case, the temperature distribution satisfies the equation. Thermo-elastic potential moves for the quasi-static case is determined by the formula:

$\Delta \Phi=\frac{1+\mu}{1-\mu} \alpha \Delta T(4)$

$\Phi(t, r, z)=\frac{1+\mu}{1-\mu} \alpha \Delta T=\beta_{0} \Delta T(5)$

$$
\beta_{0}=\frac{1+\mu}{1-\mu} \alpha T_{0}
$$

For the quasi-static case, the thermal stresses are determined by the formula by using the thermo-elastic potential of displacement.

$$
\left.\begin{array}{c}
\sigma_{r r}=\frac{\sigma_{r r}}{2 G}=\frac{d^{2} \Phi}{d r^{2}}-\Delta \Phi \\
\sigma=\frac{\sigma_{\theta \theta}}{2 G}=\frac{1}{r} \frac{d \Phi}{d r}-\Delta \Phi \\
\sigma_{z z}=\frac{\sigma_{z z}}{2 G}=\frac{d^{2} \Phi}{d r^{2}}-\Delta \Phi
\end{array}\right\}(6)
$$

Since

we have

$$
\Delta T(r, z, t)=\Delta T_{H}\left\{1-\sum_{n=1}^{\infty} \sum_{m=1}^{\infty} M_{n} B_{m} U_{0}\left(\mu_{n} \frac{r}{R_{1}}\right) \cdot \cos \mu_{m} \frac{z}{n} l^{-\frac{\left(\mu_{m}^{2}+b^{2} \mu_{n}^{2}\right)}{R_{1}^{2}} a t}\right\}
$$

$\Phi(t, r, z)=\frac{1+\mu}{1-\mu} \alpha \Delta T_{H}\left\{1-\sum_{n=1}^{\infty} \sum_{m=1}^{\infty} M_{n} B_{m} U_{0}\left(\mu_{n} \frac{r}{R_{1}}\right) \cdot \cos \mu_{m} \frac{z}{n} l^{-\frac{\left(\mu_{m}^{2}+b^{2} \mu_{n}^{2}\right)}{R_{1}^{2}} a t}\right\}(7)$

As indicated above, a row representing the solutions to non-stationary heat conduction problems quickly converges and one or two members of the series are sufficient for practical calculations.

Therefore, when $n=1, m=1$ temperature potential displacement is determined by the formula:

$$
\begin{aligned}
& \Phi(t, r, z)=\beta_{0} \Delta T_{H}\left\{1-\frac{2 B_{i_{1}} U_{0}\left(\mu_{n} \frac{r}{R_{1}}\right)}{\left.\left(\mu_{1}^{2}+B i_{1}^{2}\right)\left[\frac{R_{2}}{R_{1}} U_{0}\left(\frac{R_{2}}{R_{1}} \mu_{1}\right)\right]-\frac{2}{\pi B_{i 1}}\right]}\right. \\
& \left.\cdot \frac{2 B_{i} B i^{2}+\mu_{1}^{2}}{\mu_{1}^{2}\left(B i^{2}+B i+\mu_{1}^{2}\right)} \cos \mu_{1} \frac{Z}{n} l^{-\mu_{1}^{2}\left(\frac{\pi R_{2}}{n}\right)^{2} \frac{a t}{R_{1}^{2}}}\right\} \\
& =\beta_{0} \Delta T_{H}\left\{1-A \cos \mu_{1} \frac{z}{n} U_{0}\left(\mu_{n} \frac{r}{R_{1}}\right) l^{-A_{0} \frac{a t}{R_{1}^{2}}}\right\}(8) \\
& \left.A=\frac{2 B_{i_{1}}}{\left(\mu_{1}^{2}+B i_{1}{ }^{2}\right)\left[\frac{R_{2}}{R_{1}} U_{0}\left(\frac{R_{2}}{R_{1}} \mu_{1}\right)-\frac{2}{\pi} B_{i 1}\right.}\right] x \frac{2 B_{i} \sqrt{B i^{2}+B_{1}{ }^{2}}}{\mu_{1}^{2}\left(B i^{2}+B i+\mu_{1}^{2}\right)} \quad ; \quad A_{0}=\mu_{1}^{2}\left[1+\left(\frac{\pi R_{2}}{n}\right)^{2}\right](9)
\end{aligned}
$$

It is known, that the sum of normal stresses is a function of volumetric strain and is determined by formula: 


$$
\begin{aligned}
& \theta=\sigma_{r r}+\sigma_{\theta \theta}+\sigma_{z z}=\frac{d^{2} \Phi}{d r^{2}}+\frac{1}{2} \frac{d \Phi}{d r}+\frac{d^{2} \Phi}{d r^{2}}-3 \Delta \Phi=-2 \Delta \Phi=2 \beta_{0} \Delta T_{H} A\left[\left(\frac{\mu_{1}}{R_{1}}\right)^{2} U_{0}^{\prime \prime}{ }_{0}\left(\mu_{1} \frac{r}{R_{1}}\right)+\right. \\
& 1 r U 0 \mu 1 r R 1-U V 0 \mu 1 r R 1 \cdot \cos \mu 1 z n l-A O a t R 12(10)
\end{aligned}
$$

Numerous experiments show that the destruction of parts during their cooling and the development of plastic deformation occurs under the action of the maximum stress difference. Taking into account the above formula for the voltage difference, we obtain the following expression:

$$
\begin{gathered}
\sigma_{r r}-\sigma_{\theta \theta}=\beta_{0} \Delta T_{H} A\left[\frac{1}{r} \frac{\mu_{1}}{R_{1}} U_{0}^{\prime}\left(\mu_{1} \frac{r}{R_{1}}\right)-\left(\frac{\mu_{1}}{n}\right){ }^{2} U_{\circ}^{\prime \prime}\left(\mu_{1} \frac{r}{R_{1}}\right)\right] \cdot \cos \mu_{1} \frac{z}{n} e^{-A_{0} \frac{a t}{R_{1}^{2}}} \\
\sigma_{r r}-\sigma_{z z}=\frac{d^{2} \Phi}{d r^{2}}-\frac{d^{2} \Phi}{d r^{2}}-\beta_{0} \Delta T_{H} A\left[\frac{\mu_{1}}{R_{1}} U_{0}^{\prime \prime}{ }_{0}\left(\mu_{1} \frac{r}{R_{1}}\right)+\left(\frac{\mu_{1}}{n}\right)^{2} U_{\circ}^{\prime \prime}\left(\mu_{1} \frac{r}{R_{1}}\right)\right] \cdot \cos \mu_{1} \frac{z}{n} e^{-A_{0} \frac{a t}{R_{1}^{2}}} \\
\sigma_{r r}-\sigma_{z z}=\frac{d^{2} \Phi}{d r^{2}}-\frac{1}{r} \frac{d \Phi}{d r}=\beta_{0} \Delta T_{H} A\left[\frac{\mu_{1}}{R_{1}} U_{0}\left(\mu_{1} \frac{r}{R_{1}}\right)+\frac{1}{r}\left(\frac{\mu_{1}}{n}\right)^{2} U_{0}^{\prime}\left(\mu_{1} \frac{r}{R_{1}}\right)\right] \cdot \cos \mu_{1} \frac{z}{n} e^{-A_{0} \frac{a t}{R_{1}^{2}}}
\end{gathered}
$$

An analysis of these expressions shows that the first stress difference is the largest.Thus, the most dangerous from the viewpoint of sample cracking is the maximum stress difference $\sigma_{r r}-\sigma_{\theta \theta}$ which should be minimized. On the basis of the studies carried out, it can be concluded that in the production environment, when removing parts from the mold, depending on the material and design of the part, controlling the process parameters, it is possible to achieve the required quality of the product from thermosetting plastic materials.

\section{Luterature}

[1] Керимов Д.А.Научные основы и практические методы оптимизации показателей качества пластмассовых деталей нефтепромыслового оборудования. Дис. Д-ра техн.наук, Баку, АзИНЕФТЕХИМ, 1985

[2] Александров А.В., Потапов В.Д., Державин Б.П.Сопротивление материалов - М.: Высшая школа, 2004. - 560 с.

[3] Горшков А.Г. и др. Сопротивление материалов. М.: Физматлит, 2005

[4] Макаров Е.Г. Сопротивление материалов. СПб.: БХВ-Петербург, 2004 